\title{
A VISÃO DAS GESTANTES ACERCA DA PARTICIPAÇÃO DO HOMEM NO PROCESSO GESTACIONAL
}

\section{THE POINT OF VIEW OF PREGNANT WOMEN ABOUT THE PARTICIPATION OF MAN IN THE GESTATIO PROCESS}

\section{VISIÓN DE MUJERES EMBARAZADAS ACERCA DE LA PARTICIPACIÓN DEL HOMBRE EN EL PROCESO DE GESTACIÓN}

Letícia Ábdon Caldeira ${ }^{1}$, Lílian Fernandes Arial Ayres ${ }^{2}$, Laís Vanessa Assunção Oliveira ${ }^{1}$, Bruno David Henriques ${ }^{3}$

\section{RESUMO}

Objetivo: Analisar a visão das gestantes quanto à participação do homem durante o processo gestacional e as consultas de prénatal. Métodos: Trata-se de uma pesquisa qualitativa, avaliada por meio de análise de conteúdo, que teve como sujeitos as gestantes cadastradas em duas Estratégias de Saúde da Família. Resultados: A pesquisa apontou o apoio ofertado em âmbito familiar como essencial para a gestante e a ausência do homem durante a consulta foi entendida e justificada pelo horário de trabalho do companheiro, na maioria das vezes. Conclusão: Assim, depreende-se que existe a necessidade de estabelecimento de vínculo entre a tríade mãe-pai-filho para o melhor desenvolvimento da gestação. Os profissionais de saúde envolvidos na Atenção Primária à Saúde podem contribuir para esse processo e devem estimular e facilitar a participação do homem durante as consultas de pré-natal, entre outras atividades realizadas nesse cenário.

Descritores: Paternidade; Cuidado pré-natal; Apoio social; Gravidez.

\section{ABSTRACT}

Objective: To analyze the point of view of pregnant women as man's participation during the gestational process and prenatal consultations. Methods: This is a qualitative study, evaluated by content analysis, which had as it subject the pregnant women registered in a health unit. Results: The study showed that the support offered in the family environment as essential to the pregnant woman and the absence of the man during the consultation were understood and justified by fellow working hours. Conclusion: Thus, it appears that there is a need for establishment of a connection between the mother-father-child triad for the optimal development of pregnancy. Health professionals involved in primary health care can contribute to this process and should encourage and facilitate the participation of man during the prenatal consultations, among other activities performed in this scenario.

Descriptors: Paternity; Prenatal care; Social support; Pregnancy.

\section{RESUMEN}

Objetivo: Analizarla visión de mujeres embarazadas en cuanto la participación del hombre durante el proceso de gestación y las consultas de prenatal. Método: Se trata de una investigación cualitativa, evaluada por análisis del contenido, que tenia como sujetos las mujeres registradas en una unidad de salud. Resultados: La pesquisa mostró que el apoyo ofrecido en el entorno familiar como esencial a la embarazada y la ausencia del hombre en la consulta fue entendida y justificada por el horario de trabajo del compañero. Conclusión: Así, pues, puede se desprender que hay necesidad de establecimiento de un vinculo entre la tríada madre-padre-hijo para lo mejor desarrollo de la gestación. Los profesionales de salud involucrados en la Atención Primaria a la Salud pueden contribuir a este proceso y deben estimular y facilitar la participación del hombre en las consultas de prenatal, entre otras actividades realizadas en este evento.

Descriptores: Paternidad; Atención prenatal; Apoyo social; Embarazo.

${ }^{1}$ Graduada em enfermagem pela Universidade Federal de Viçosa. ${ }^{2}$ Graduada em Enfermagem. Doutorado em Enfermagem e Biociências. Professor Adjunto da Universidade Federal de Viçosa. ${ }^{3}$ Graduado em Enfermagem. Doutor em Ciências da Saúde. Docente na Universidade Federal de Minas Gerais. 


\section{INTRODUÇÃO}

O conceito de humanização do pré-natal, do parto e do nascimento é amplo e envolve práticas e atitudes com o objetivo de promover o parto e o nascimento de forma saudável, prevenindo a morbimortalidade materna e perinatal, e de proporcionar acolhimento e atendimento de qualidade ${ }^{(1)}$. 0 pré-natal consolidou-se como uma maneira eficaz de garantir bom prognóstico à gestante e de assegurar o desenvolvimento adequado da gestação, além de proporcionar o parto e o nascimento com reduzido impacto à saúde da mulher e do recém-nascido ${ }^{(2-3)}$.

Durante as consultas a mulher pode sanar suas dúvidas, expressar seus medos e suas inseguranças e tomar decisões no que diz respeito à sua gestação, ao tipo de parto que deseja, entre outras. Neste contexto, a presença paterna torna-se essencial, pois deve ser entendido como uma etapa de preparo dos pais para 0 nascimento, 0 que estabelece 0 sentimento de companheirismo, compartilhamento de situações e entrega, além de oferecer condições propícias para vivenciar a paternidade ainda na gestação, como forma de materialização da criança ${ }^{(4-5)}$.

A paternidade é um conceito repleto de estigmas culturais, religiosos e familiares que determinam o envolvimento afetivo do homem no contexto familiar. Estes fatores definem como o pai irá vivenciar o momento, interferindo na relação entre homem-mulher e pai-filho. Para muitos, o sentimento de "ser pai" se expressa posteriormente ao nascimento, o que, em geral, afeta a maneira de lidar com a gestação. Com isso, o envolvimento do homem nas consultas de pré-natal gera a oportunidade de aproximação da tríade mãe-pai-filho, além de minimizar as dúvidas e fazer com que ambos, pai e mãe, sintam a necessidade do cuidado e de ser cuidador, predispondo a família a um estado de bem-estar ${ }^{(4,6-7)}$.

Vale ressaltar que o modo como o homem se insere durante o pré-natal dá indícios de como ele irá lidar com os outros momentos do ciclo gravídico-puerperal. 0 envolvimento nas consultas favorece sua participação no momento do parto, que se faz tão necessária e benéfica para a mulher quanto nas demais fases da gestação $^{(4,5)}$. Existe a necessidade constante de estar em uma relação que traduza apoio, afeto e segurança. O companheiro, ao participar das consultas de pré-natal, viabiliza a satisfação dessas necessidades, proporciona maior vínculo nas relações e favorece os cuidados com a saúde da mulher.

No entanto, quando ele se exclui ou é retirado desse contexto ocorre o aparecimento de sentimentos como ciúmes, ansiedade e solidão, consequentemente as demandas da mulher não são atendidas. A gravidez pode ser vista como uma ameaça, fato que pode interferir na relação da tríade mãe-pai-filho ${ }^{(6)}$. 0 sentimento de exclusão do pai pode ser devido à relação familiar, que pode estar afetada pela gestação, ou ao não incentivo dos profissionais e da própria sociedade, que primariamente voltam sua atenção para a saúde da mulher e da criança, atribuindo ao pai a única função de provedor, o qual toma uma atitude expectante diante da gestação $^{(8)}$.

Mesmo com os benefícios da participação do companheiro nas consultas de pré-natal, estudos como os de Francisco et al. ${ }^{(4)}$, Silva ${ }^{(8)} \mathrm{e}$ Gomes et al. ${ }^{(9)}$. indicam a ausência do homem durante esse momento. Os autores apontam como principais causas os fatores externos, dentre os quais cabe destacar o horário de trabalho. Além disso, Lima ressalta que quando o nível de escolaridade do casal é mais elevado, há maior adesão por parte da mulher ao pré-natal, e a participação do homem durante o ciclo gravídico-puerperal é mais ativa ${ }^{(10)}$.

A presença do homem durante o trabalho de parto configura-se como uma tecnologia não invasiva para o alívio da dor, proporciona apoio, minimiza a ansiedade e reduz o tempo de trabalho de parto. Portanto, sua inserção nesse momento, assim como no pré-natal, traz inúmeras vantagens para a mulher e também para a transição que se concretiza na vida do homem, que passa a viver efetivamente a paternidade ${ }^{(11)}$. Essa situação proporciona uma paternagem mais segura, participativa e digna.

Instituto Promundo ${ }^{(6)}$, e Gomes et al. ${ }^{(9)}$ afirmam que o homem, ao sair da postura de expectante e ao se enxergar de maneira atuante e participativa durante o parto, passa a vivenciar a paternidade de forma real, sobretudo quando esteve presente nas consultas de pré-natal. Silva ressalta que essa participação pode ocorrer de 
diferentes formas e que o fato de não estar presente durante as consultas não significa falta de suporte do companheiro ${ }^{(8)}$. Acrescenta que as mulheres afirmam que $o$ interesse $e \quad a$ preocupação que os homens demonstram no lar suprem sua ausência no atendimento de prénatal, sendo suficiente para atender às suas maiores demandas ${ }^{(12)}$.

Diante dos benefícios apresentados, compreende-se que estudos relacionados com a participação do pai no processo de gestar, parir e maternar devem ser sempre incentivados e realizados. Partindo deste pressuposto, e daquele em que houve aumento da cobertura de prénatal no município de Viçosa-MG e a participação paterna neste processo é desconhecida, surgiu a seguinte indagação: Qual é a visão das gestantes atendidas em uma unidade de Atenção Primária à Saúde do município de Viçosa, MG, sobre a ausência ou a presença do companheiro durante o processo gestacional e as consultas de prénatal?

\section{MÉTODOS}

Este estudo tem uma abordagem qualitativa, uma vez que busca conhecer a subjetividade dos sujeitos da pesquisa, ou seja, suas opiniões, seus sentimentos e suas vivências com relação à participação do companheiro durante o período gravídico ${ }^{(13)}$.

A pesquisa foi realizada em um bairro do município de Viçosa, MG, com atuação do projeto de Extensão "O grupo educativo como forma de cuidado do casal grávido, puérperas e familiares" do curso de Enfermagem da Universidade Federal de Viçosa - UFV. Esse projeto está sendo desenvolvido há aproximadamente quatro anos, trabalhando com grupos educativos e realizando visitas domiciliares. Por meio dele, a pesquisadora, integrante desse projeto de extensão, estabeleceu vínculo com as gestantes, fator que favoreceu o desenvolvimento das entrevistas. Além disso, esse cenário possui duas equipes da Estratégia Saúde da Família - ESF que oferecem atendimento de pré-natal e de acompanhamento das gestantes e das puérperas.

Foram incluídas gestantes com idade superior a 18 anos, residentes em Viçosa (MG), que são acompanhadas e realizam o pré-natal nas ESF'S do bairro em questão e que aceitaram participar. As mulheres foram abordadas em visita domiciliar agendada pelo Agente Comunitário de Saúde. O ACS acompanhou o entrevistador até a residência, porém não participou da coleta de dados, como forma de garantir a privacidade das mulheres. As entrevistas duraram aproximadamente 15 minutos. Os dados foram coletados por meio de entrevista com roteiro semiestruturado, por proporcionar maior liberdade para as respostas, além de permitir a elaboração de novas indagações. O roteiro contou com questões de identificação da participante, com dados como: idade, escolaridade, raça (autorreferida), idade gestacional, dentre outros que permitiram traçar o perfil social e obstétrico das participantes em estudo. Em seguida foram feitas as indagações: 1) O que significa pra você a participação do seu companheiro na gestação? 2) Como você se sente/sentiria com a presença do seu companheiro durante o pré-natal? As mulheres foram identificadas por meio de números, em ordem aleatória, para melhor garantir o anonimato das participantes.

Utilizou-se a técnica de "Análise de Conteúdo" na perspectiva de Bardin. Trata-se de uma etapa definida por Caregnato e Mutti como uma técnica de pesquisa que visa à descrição do conteúdo do manifesto de comunicação de maneira objetiva, sistemática e quantitativa. Nessa proposta, o texto é visto como a forma de expressão dos sujeitos, no qual o pesquisador busca categorizar as palavras-chaves, inferindo uma expressão que as representem ${ }^{(15)}$. Sendo assim, o objetivo deste estudo foi descrever o conteúdo da mensagem, permitindo a inferência de conhecimentos advindos do texto referentes às condições de produção e à sua percepção.

A aplicação da técnica ocorre em três etapas: 1) leitura flutuante, que consiste em apreender e organizar de forma não estruturada aspectos importantes para as próximas fases da análise; 2) seleção das unidades de análise, ou seja, identificação de frases, palavras, fragmentos de textos ou textos completos que vislumbrem o objetivo da pesquisa; e 3 ) processo de categorização, que consiste em definir categorias que abarcam temas variados, sendo estes definidos por grau de proximidade e, por meio de sua análise, pelos seus significados ${ }^{(15)}$. A partir desse processo analítico, emergiram duas categorias: "A visão das mulheres sobre a participação do homem durante a gestação"; e "Sentimentos desencadeados pela presença ou ausência do companheiro durante a consulta de pré-natal". As respostas advindas dessas questões foram analisadas e discutidas com base em estudos pertinentes ao tema. 
O término da coleta foi determinado quando houve saturação dos dados, ponto em que não havia mais acréscimo de informações ou mudanças na compreensão do fenômeno em estudo $^{(15)}$.

A pesquisa foi aprovada pelo Comitê de Ética e Pesquisa (CEP) com seres humanos da UFV, sob o parecer 032736/2014.

\section{RESULTADOS E DISCUSSÃO}

A coleta foi feita no período de maio a julho de 2014, totalizando 11 entrevistas, tendo sido excluída uma, pelo fato de a gestante não possuir contato com o companheiro e não desejar participar do estudo. Sendo assim, dez entrevistas foram analisadas. A média de idade das participantes foi de 26,3 anos, tendo duas se autorrefererido como da raça negra, quatro brancas, duas mulatas, uma parda e uma afirmou ser amarela. A média de idade gestacional encontrada foi de 20,8 semanas, quatro primíparas, seis multíparas com média de 2,6 filhos. Das mulheres entrevistadas, apenas uma apresentou histórico de abortamento, relata cinco gestações, sendo que duas evoluíram para perda. Constatou-se que cinco participantes possuem ensino fundamental incompleto e o restante ensino médio completo. Com relação à participação do companheiro, apenas três gestantes afirmaram ter sido acompanhadas em pelo menos uma consulta de pré-natal, o que demonstra a mínima participação do homem nesse cenário, o que confirma os resultados obtidos por Francisco et al. ${ }^{(4)}$, Silva ${ }^{(8)}$ e Lima ${ }^{(10)}$.

A justificativa mais prevalente para a não participação do companheiro nas consultas está relacionada ao horário de trabalho deste. Sete mulheres responderam que o horário de atendimento às gestantes era inapropriado para que companheiro pudesse acompanhá-la. Essa situação evidencia a importância da melhor adequação dos horários ofertados pelos serviços de saúde na atenção à saúde da mulher grávida e, ou a garantia legal da ausência paterna das atividades laborais nos horários das consultas de pré-natal, a fim de permitir sua participação.

Quando questionadas a respeito da participação do companheiro durante a gravidez, as expressões de sentimentos utilizados pela maioria das gestantes foram de segurança, força e alegria, dentre outros. Algumas mencionaram o apoio como forma de participação durante a gestação. Esses dados resultaram na formulação de duas categorias.

\section{A visão das mulheres sobre a participação do homem durante a gestação}

Ao analisar as entrevistas, percebe-se que a maioria das mulheres cita o apoio do companheiro como a principal forma de participação durante o período gestacional, o qual ocorre de distintas maneiras dentro do contexto familiar e na intimidade dos lares. 0 apoio pode ser definido como "apoio social" e "redes sociais". O apoio social caracteriza-se pelas relações formais e informais, das quais o indivíduo recebe ajuda emocional, cognitiva e material para enfrentar as situações promotoras de estresse. Já as redes sociais referem-se às redes de relações mantidas pelos indivíduos, sendo consideradas fontes do apoio social ${ }^{(16-17)}$.

Compreende-se que durante o período gestacional a mulher se encontra em estado de labilidade emocional, o que influencia não apenas a gestante, mas também a família, pois afeta o seu estilo de vida e o papel desempenhado pelos seus membros ${ }^{(18)}$. Deste modo, o apoio social torna-se fundamental para o enfrentamento de situações geradoras de estresse. O companheiro, normalmente, é visto como a principal fonte desse apoio e a aceitação da gestação pelo homem-pai tem influência importante na interação mãe-feto/mãe-bebê $\hat{~}^{(16)}$. Esse fator pode ser percebido na fala de G-II, G-III, GIV e G-XI, respectivamente: “(...) Deixa a gente até mais calma"; "(...) A mulher fica carente sem o apoio do homem, é muito ruim se não tiver o apoio dele"; “(...)Ele participar da minha gestação?! Se preocupar: 'você esta tomando as vitaminas? Você ta fumando? Você esta bebendo? Esta mexendo? Você ouviu o coraçãozinho? Já sabe o que que é, se é homem, se é mulher, se é os dois?'. É ter aquela, preocupação gostosa assim; Não vou falar de marido, que eu não sou obrigada a ser casada de novo. Mas, de companheiro (...)"; "A gente tem mais força, por que ele que falou comigo, me deu força pra mim não ficar desesperada, pra mim não ficar do jeito que eu fiquei. Por que eu fiquei muito, mais muito nervosa mesmo. Eu fiquei só pensando como é que iria ser. Mas ele me deu muita força, assim; tá me dando."

A partir dessas afirmativas, percebe-se que quando o companheiro interage de forma positiva com a gestação, dispensando à mulher não apenas suporte financeiro, mas também emocional, o vínculo estabelecido entre a díade mãe-feto se intensifica, fazendo com que as 
alterações gravídicas sejam superadas com maior facilidade. Consequentemente, durante esse período seu comportamento em relação à saúde tende a tornar-se mais positivo, havendo maior estímulo à diminuição do tabagismo, do alcoolismo, dentre outros vícios, assim como a aceitação da gestação pela mulher, como percebido na fala de G-XI. Além disso, proporciona maior solidez nas relações familiares $^{(19-21)}$.

No que se refere à participação do homem nas atividades domésticas, percebe-se na fala de G-IX que a mulher entende o apoio do parceiro como favor ou ajuda, indo além de suas obrigações como provedor do lar, o que é gratificante aos olhos dela: "Ele me ajuda do jeito que ele pode! Me ajuda a cuidar dos meninos, o que ele puder fazer ele faz". Por meio deste relato constata-se que a mulher não consegue compreender que a participação do pai pode ser maior que as suas funções atribuídas durante anos, conforme estabelecido pelo modelo patriarcal. Essa situação reforça a carga cultural imposta pela sociedade no que toca aos papéis do homem e da mulher no relacionamento familiar $^{(4,22-23)}$.

No entanto, estudos mostram que desde o final do século passado o homem vem assumindo um novo papel no âmbito familiar, deixando de lado o comportamento rígido, de mantenedor, e passando a assumir atribuições até então destinadas à mulher. Esse fator faz com que se altere também o conceito de paternidade, pois hoje o pai participativo, que cuida e zela pelos filhos e divide com a mulher as preocupações da gestação, torna-se cada vez mais comum e vem sendo cobrado pela sociedade atual, como observado nos relatos de G-VIII e G-X: "Seria bom pra ele ajudar a cuidar do neném. É importante também, por que nós somos um casal" (G-VIII); "É o pai, tem que estar presente" $(\mathrm{G}-\mathrm{X})^{(22)}$.

Cabe destacar que essas mudanças estão intimamente relacionadas à entrada da mulher no mercado de trabalho, o que exigiu a reorganização da estrutura familiar e, consequentemente, do conceito de paternidade, como citado anteriormente ${ }^{(21-22)}$. Em contrapartida, a participação em uma consulta de pré-natal pode ser vista não como fonte de apoio, mas como perda de autonomia, como percebido na fala de G-III: "Eu acho que isso é ruim. Se ele estivesse nas consultas, ele ia interferir, ele consultaria pra mim, aí eu acho que não ia ajudar muito não".

$\mathrm{O}$ relato anterior remete à afirmação de Rousseau, no século XVIII, de que a mulher é incapaz de julgar por si mesma, enfatizando ainda que ela deveria sempre ater-se ao juízo de seus pais e de seu marido. Constata-se que a visão histórica e cultural da mulher influencia o modo como a sociedade lida com sua independência e a nova postura social assumida por ela nas últimas décadas $^{(23)}$. Essa situação reforça a submissão da mulher e a desigualdade entre os sexos, que se expressa nas categorias hierárquicas construídas na história da sociedade, que classifica o status dos gêneros. Quando G-III afirma que "ele consultaria pra mim", fica evidente a perda de autonomia da mulher, que pode ser definida como "a capacidade e as condições concretas que permitem a tomada de decisão que afetam sua vida e o poder de agir conforme essas decisões"(21-24).

Desta forma, quando o homem interfere na tomada de decisão da mulher, independentemente da situação em que se encontra, ele retira a autonomia e seu poder de decisão sobre sua própria vida. Contudo, a mulher nem sempre percebe essa ocorrência, que pode ser entendida, segundo Bourdieu (1998), como uma "violência suave, insensível, invisível a suas próprias vítimas, que se exerce essencialmente pelas vias puramente simbólicas da comunicação e do conhecimento, do reconhecimento ou, em última instância, do

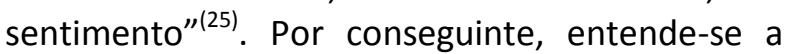
atitude desse companheiro como uma violência simbólica, objetivando tornar a mulher um ser passivo e submisso à sua cultura, às suas crenças e aos seus valores ${ }^{(25)}$.

Diante do exposto, fica evidente que a participação do homem durante o período gravídico-puerperal não deve se resumir à sua inserção durante as consultas de pré-natal. Sua participação nos eventos cotidianos, a preparação para receber o bebê e o cuidado com a mulher são formas de apoio que a satisfaz, pois proporciona um ambiente de segurança, acolhedor e que incentiva a gestante a busca de maior contato com o bebê e também diminuição da ansiedade e preocupação ${ }^{(26)}$.

Porém, não pode ater-se apenas a esse fator, é preciso compreender a necessidade de que a atenção pré-natal esteja centrada na família, dispensando cuidado não apenas à mulher e à criança, mas ao casal. É imprescindível 
proporcionar ao homem o exercício de seu direito de estar presente e fazer parte desse momento, não apenas durante o parto, mas em todo o período gravídico-puerperal, pois são inúmeras as vantagens tanto para o cuidado com a saúde da mulher, quanto da família. Vale salientar que a mudança no conceito de paternidade afeta o modo como o homem se insere nesse contexto, o que é crucial para a interação pai-filho, consequentemente afeta esse relacionamento durante o crescimento e o desenvolvimento da criança $^{(6)}$.

Sendo assim, é preciso identificar como o companheiro se insere na gestação, para que os profissionais que realizam o pré-natal (médicos e enfermeiros) possam atuar de maneira que atinja a família. Identificar sua participação no lar é preponderante para entender as necessidades biopsicossociais da mulher e do seu companheiro e, ainda, ofertar o cuidado e as orientações adequadas à tríade mãe-pai-filho. Além disso, cabe aos profissionais de saúde apresentar ao casal os seus direitos como pai, mãe, gestante, parturiente e puérpera, para que eles possam fazer valer as leis e exercer seus direitos de cidadãos. É preciso repensar as formas de atenção à saúde e buscar a qualificação da assistência assim como definido pela Portaria GM no 569 de 01/06/2000 que instituiu o Programa de Humanização do Pré-natal e nascimento para que se possa realmente efetivar uma assistência qualificada, humanizada e centrada na família, assegurando, assim, maior bem-estar ${ }^{(1)}$.

\section{Sentimentos desencadeados pela presença ou ausência do companheiro durante a consulta de pré-natal}

Os sentimentos são as formas encontradas pelos indivíduos de expressarem as experiências vivenciadas. Sua definição, na terminologia psicoclínica, configura-se como ampla e abstrata, sendo as experiências capazes de causar alterações na subjetividade do sujeito que dão origem aos sentimentos. Estes são processos de natureza exclusivamente psíquica que podem acompanhar as sensações, mas não possuem relação de dependência com os objetos, e sim com os sujeitos ${ }^{(27)}$. Os objetos são determinados como as experiências humanas internalizadas e os sujeitos, como aqueles que vivenciam essas experiências, de tal forma que o objeto é extraído do sujeito e gera hipóteses acerca da realidade ${ }^{(28)}$.

Ao questionar as participantes como se sentiriam ou sentiram com a participação do companheiro durante a consulta de pré-natal, nota-se a presença de muitos sentimentos. Quase a totalidade das mulheres a referiu de forma positiva, mencionando sentimentos como segurança, alegria e confiança, como observado nas falas a seguir: "Foi tudo pra mim por que ele sempre está do meu lado pra tudo. Então pra gente é tudo novidade, a gente fica alegre" (G-I); "Ah, eu acho que me sentiria mais segura. Por que acho que ele dá uma força a mais pra gente. Mais confiança" (G-IX); "eu me sentiria bem, não me incomodaria não" (G-VI); "É bom ele vim, pra ele ouvir tudo que o médico estiver falando. Participar comigo" (G-VII).

Do ponto de vista psicanalítico, os sentimentos referidos estão associados à necessidade desenvolvida pela mulher, durante o período gestacional, de maior proteção e amparo. Essa necessidade ocorre devido à gestação desencadear uma experiência regressiva, que leva a gestante a vivenciar, de forma intensa, sentimentos de ansiedade e abandono. Partindo do pressuposto que o maior suporte emocional durante a gestação, segundo as mulheres, é dispensado pelo companheiro, pai do bebê, conclui-se que sua participação durante o prénatal é tão necessária quanto o apoio concedido no âmbito familiar, desde que seja um desejo da mulher $^{(27)}$. Cabe evidenciar que a presença do homem é solicitada pela mulher não apenas nas consultas, mas também nos exames de imagem, como ultrassonografia (USG). Destacam-se as falas de G-VI e G-XI respectivamente: “(...) no ultrassom da minha primeira ele teve comigo, então eu me senti bem melhor, pelo menos eu sabia que ele estava ali comigo naquela hora (...)"; "Me fez mais falta foi ele nas ultrassons, mas na consulta, em si, não... eu nem cobro dele".

Pode-se justificar essa necessidade da mulher em ter a presença do companheiro durante a USG, devido à emergência em sanar dúvidas com relação ao bem-estar e à saúde fetal. Para o homem, é uma possibilidade de estabelecer maior contato com o bebê $\hat{e}^{(26)}$. Estes fatores também foram identificados na fala de G$\mathrm{XI}$ : "Por que assim, a primeira ultrassom que eu fiz, por ele ter ficado tão animado, pra saber e tudo. E quando eu fui saber o sexo também, por que ele queria muito, mas como eu marquei de manhã. Foi só essa parte mesmo..., pra ele poder ver, que ele fica ansioso, querendo ver".

Constata-se que a USG é um momento de emoções intensas entre o casal, além de 
fortalecer a relação dos pais com o bebê. Este possibilita ao homem visualizar os contornos do feto pelo visor do aparelho de USG e ainda escutar os batimentos do coração. Todos os aspectos imaginários com relação ao bebê são alvo de investigação, em razão do desejo de identificar a saúde, o sexo, o peso e o comprimento do filho. Esses fatores, na maioria das vezes, asseguram que o feto está saudável e que a gestação poderá seguir seu curso sem problemas relacionados ao bebêt $\hat{e}^{(26)}$.

Além disso, o profissional de saúde, na presença do casal, pode utilizar a técnica da Haptonomia para estimular o vínculo da tríade mãe-pai-feto durante as consultas de pré-natal, e assim estimular o sentimento do pai de estar tão ligado à criança quanto à figura materna. A técnica, que ganhou esse nome há mais de 50 anos, foi desenvolvida no século $X X$ por FransVeldman, que tinha como objetivo definir a "Ciência da Afetividade". Ela é utilizada para desenvolver a comunicação intrauterina, principalmente por meio do toque no abdome gravídico, que auxilia no desenvolvimento de um estado de segurança para a criança, além de estimular seu desenvolvimento tanto durante a gestação, quanto após o nascimento. Ela também se configura como uma forma de preparo dos pais para receber o bebêt(29).

Essa técnica permite o desenvolvimento da paternidade e da maternidade ainda na gestação, pois estimula o sentimento de responsabilidade dos pais com relação à criança, pensando-a como ser humano, ultrapassando os limites do imaginário que muitas vezes persiste até o nascimento ${ }^{(27)}$. Compreende-se que a Haptonomia permite maior interação entre o casal, favorecendo o desenvolvimento de sentimentos como segurança e proteção. $O$ homem passa a vivenciar, junto com a mulher, experiências e sensações únicas até então particularizadas à gestante.

"Quanto ao pai, algumas vezes excluído da relação psicológica mãe-feto, ele encontra um meio excepcional de entrar em contato com o filho antes do nascimento" ${ }^{\prime 29)}$. A Haptonomia minimiza a diferença entre a vivência do pai em relação àquela que a mãe possui com o bebê. Aliás, a prática desta técnica deve ser realizada na presença do pai, de forma a fortalecer esse vínculo.

O profissional de saúde que conhece a técnica pode, durante as consultas ou os encontros do grupo educativo, orientar os pais sobre sua realização, para que muitos conflitos sejam superados e o vínculo e o afeto se intensifiquem entre mãe-pai-feto. Com isso, a paternidade se constitui como a maternidade, sem diferenças culturais que classifiquem o homem apenas como o provedor. Ele passa a ser visto como um indivíduo atencioso e participativo no desenvolvimento da criança, colaborando, assim, para o estabelecimento do novo conceito de paternidade.

Contrapondo-se a essa visão, uma parcela das participantes alegou ter vergonha da presença do companheiro, o que pode ser comprovado nos relatos a seguir: "Ah, eu acho que eu ficaria mais com vergonha."(G-III); "Ah, eu ficaria com um pouco de vergonha! Fala uns negócios lá que por mais que eu seja casada dá vergonha na gente" (G-VIII).

Esse sentimento pode estar relacionado não só com a presença do companheiro, mas com o sentimento de insatisfação relacionado às alterações gravídicas, que podem estar sendo vividas de maneira negativa, fazendo com que a mulher se sinta insegura com relação à sua imagem e sexualmente incapaz. Essa sensação leva à repulsa à demonstração de carinho do companheiro, acreditando que ele deseja apenas consolá-la ${ }^{(26)}$. Por conseguinte, entende-se o sentimento de vergonha como uma expressão dessa sensação, e acredita-se que a presença do companheiro durante as consultas é uma forma de expor as modificações não aceitas, promovendo o constrangimento da mulher.

É necessário que o profissional de saúde seja capaz de reconhecer esse sentimento e de identificar a história da gestante, sua relação com seu corpo, como também a sua relação com o parceiro e como este interage com a gestação e percebe as alterações causadas por ela. A escuta sensível e as orientações são essenciais para que a mulher possa demonstrar esses sentimentos. Essa situação pode alterar sua visão da gestação e contribuir para que ele vivencie esse processo como algo simples, natural e sem transtornos.

É imprescindível aos profissionais de saúde a identificação de fatores psicossociais durante as consultas de pré-natal, sejam eles positivos ou negativos, pois estes interferem nas condutas a serem adotadas e na forma como o processo será conduzido.

\section{CONSIDERAÇÕES FINAIS}

Neste estudo identificou-se a necessidade de as gestantes entrevistadas, residentes em um 
bairro de Viçosa, MG, receberem maior apoio e segurança de seus companheiros. Condições que proporcionam alegria, confiança e força, sentimentos que favorecem o bem-estar, a aceitação da gestação e de suas possíveis alterações biopsicossociais.

É evidente que a presença do companheiro nas consultas de pré-natal não é dispensada na maioria dos casos, mas sua ausência é compreendida e justificada pelo horário de trabalho. As mulheres percebem a presença do homem nesse cenário como importante, mas não indispensável, pois consideram mais a sua participação em âmbito familiar.

Depreende-se que existe a necessidade de estabelecimento de vínculo entre a tríade mãepai-filho. Os profissionais de saúde envolvidos nas APS podem contribuir para esse processo e devem estimular e facilitar a participação do homem durante as consultas de pré-natal, entre outras atividades realizadas nesse cenário. Consequentemente 0 homem passará a compreender e aceitar as mudanças biopsicossociais que ocorrem com a gestante nessa fase. Cabe ao profissional explicitar essas alterações, esclarecer e sanar as dúvidas, explicar sobre a prática da Haptonomia e reduzir os medos e anseios conforme as demandas singulares de cada casal. Assim, o profissional proporciona uma prática que favorece a vivência do ciclo gravídico puerperal de uma forma mais prazerosa e feliz, uma vez que se estabelece o vínculo mãe-pai-feto e o estimulo à maternidade e à paternidade coetaneamente.

No entanto, é necessário apreender o significado e a visão atribuídos ao processo gestacional e às consultas de pré-natal no que se refere à família, sobretudo ao pai. Para isso, sugere-se a realização de estudos semelhantes com futuros pais, uma vez que é importante assimilar como eles enxergam e compreendem o processo de gestar, a necessidade e as formas de dar apoio à companheira grávida. Acredita-se, também, que compreender a visão do pai permitirá aos profissionais de saúde formular estratégias de intervenções que favorecem e estimulem a participação do homem, garantindo, assim, o exercício efetivo da paternidade.

\section{REFERÊNCIAS}

1. Malheiros PA, Alves VH, Rangel TSA, Vargens OMC. Parto e nascimento: saberes e práticas humanizadas. Texto Contexto Enferm. 2012;21(2):329-37.
https://doi.org/10.1590/S010407072012000200010

2. Costa DKP, Arruda LP, Magalhães AHR, Abreu LDP, Ponte KMA, Freitas CHA. Cuidados de enfermagem no pré-natal e segurança do paciente: revisão integrativa. Rev Enferm UFPE. 2016;10(6):4909-19. https://doi.org/10.5205/reuol.8200-71830-3SM.1006sup201625

3. Gomes RNS, Filha FSSC, Portela NLC. Avaliação da influência do abandono da assistência pré-natal na mortalidade fetal e neonatal. J. res.: fundam. care. online. 2017;9(2):16-421. https://doi.org/10.9789/21755361.2017.v9i2.416-421

4. Francisco BS, Souza BS, Vitório ML, Zampieri MFM, Gregório VRP. Percepções dos pais sobre suas vivências como acompanhantes durante $o$ parto e nascimento. Rev Min Enferm. 2015;19(3):567-75. https://doi.org/10.5935/1415-2762.20150044 5. Maas AJ, Vreeswijk CM, Cock ES, Rijk CH, Bakel HJ. "Expectant parents": study protocol of a longitudinal study concerning prenatal (risk) factors and postnatal infant development, parenting, and parent-infant relationships. BMC Pregnancy Childbirth. 2012;12(46). https://doi.org/10.1186/1471-2393-12-46 6. Instituto Promundo. Programa P: manual para o exercício da paternidade e do cuidado. Rio de Janeiro: Instituto Promundo; 2014.

7. Brito RS, Soares JDD, Carvalho JBL, Santos DLA. Dificuldades vivenciadas pelo homem durante a gravidez da companheira. Rev RENE. 2013;2(14):272-9. Disponível em: http://www.periodicos.ufc.br/rene/article/view/ 3373/2611

8. Silva FCB. Experienciando a ausência do companheiro nas consultas de pré-natal [dissertação]. Natal: Universidade Federal do Rio Grande do Norte; 2009. Disponível em: http://repositorio.ufrn.br:8080/jspui/handle/123 456789/14671

9. Gomes R, Albernaz L, Ribeiro CRS, Moreira MCN, Nascimento M. Linhas de cuidados masculinos voltados para a saúde sexual, a reprodução e a paternidade. Cienc Saúde Coletiva. 2016;21(5):1545-52.

https://doi.org/10.1590/1413-

81232015215.26842015

10. Lima FLA. Construção da identidade paterna: repercussões no pré-natal masculino [tese]. João Pessoa: Universidade Federal da Paraíba; 2014. 
Disponível em:

http://tede.biblioteca.ufpb.br/handle/tede/7644

11. Jardim DMB, Penna CMM. Pai-

acompanhante e sua compreensão sobre o processo de nascimento do filho. REME Rev Min Enferm. 2012;16(3):373-81.

https://doi.org/S1415-27622012000300009

12. Ferreira IS, Fernandes AFC, Lô KKR, Melo TP, Gomes AMF, Andrade IS. Perceptions of pregnant women about the role of partners in prenatal consultations. Rev Rene. 2016;17(3):318-23. Disponível em: https://doi.org/10.15253/21756783.2016000300003

13. Cabrita BAC, Silveira ES, Souza AC, Alves VH. $A$ ausência do companheiro nas consultas de prénatal: desafios e conquistas. Rev Pesq Cuid Fundam. 2012;4(3):2645-54.

https://doi.org/10.9789/2175-

5361.2012.v4i3.2645-2654

14. Fontanella BJB, Magdaleno JR. Saturação teórica em pesquisas qualitativas: contribuições psicanalíticas. Psicol Estud. 2012;17(1):63-71. https://doi.org/10.1590/S1413-

73722012000100008

15. Caregnato RCA, Mutti R. Pesquisa qualitativa: análise de discurso versus análise de conteúdo. Texto Contexto Enferm. 2006;15(4):679-84.

https://doi.org/10.1590/S010407072006000400017

16. Souza WPS et al. Gravidez tardia: relações entre características sociodemográficas, gestacionais e apoio social. Bol Psicol.

2016;66(144):47-59. Disponível em:

http://pepsic.bvsalud.org/scielo.php?script=sci a rttext\&pid=S000659432016000100006\&lng=pt\&nrm=iso

17. Thomaz NSRB. Associação do apoio social materno com a velocidade de crescimento linear de zero a seis meses [dissertação]. Rio de Janeiro: Escola Nacional de Saúde Pública Sergio Arouca; 2012. Disponível em:

http://bvssp.icict.fiocruz.br/lildbi/docsonline/get. php?id=3338

18. Ricci SS. Enfermagem materno-neonatal e saúde da mulher. Rio de Janeiro: Guanabara Koogan; 2015.

19. Silva BT, Silva MRS, Bueno MEN. Eventos intra e extrafamiliar significativos no processo de construção da paternidade. Esc Anna Nery. 2014;18(4):710-5. https://doi.org/10.5935/14148145.20140101

20. Santos PFBB, Santos ADB, Mota GM, Galhardo TF, Medeiros ER. Significados da maternidade/paternidade para adolescentes que vivenciam esse processo. Rev Enferm Cent.-Oeste Min. 2015;5(2):1629-42.

https://doi.org/10.19175/recom.v0i0.819

21. Guedes RN, Fonseca RMGS. A autonomia como necessidade estruturante para o enfrentamento da violência de gênero. Rev Esc Enferm USP. 2011;45(n esp 2):1731-5.

https://.doi.org/10.1590/S0080$\underline{62342011000800016}$

22. Silva EM, Marcolino E, Ganassin GS, Santos Al, Marcon SS. Participação do companheiro nos cuidados do binômio mãe e filho: percepção de puérperas. J Res Fundam Care. 2016;8(1):39914003. https://doi.org/10.9789/21755361.2016.v8i1.3991-4003

23. Amaral BS. Autonomia feminina e igualdade relativa: uma análise crítica da violência de gênero [trabalho de conclusão de curso]. Porto Alegre: Universidade Federal do Rio Grande do Sul; 2013. Disponível em: http://hdl.handle.net/10183/91029

24. Salvini L, Souza J, Marchi Junior W. A violência simbólica e a dominação masculina no campo esportivo: algumas notas e digressões teóricas. Rev Bras Educ Fis Esp. 2012;26(3):40110. https://doi.org/10.1590/S1807$\underline{55092012000300006}$

25. Bourdieu P. A dominação masculina. 11a ed. Rio de Janeiro: Bertrand Brasil; 1998.

26. Simas FB, Souza LV, Scorsoline-Comin F. Significados da gravidez e da maternidade: discurso de primíparas e multíparas. Psicol Teor Prat. 2013;15(1):19-34. Disponível em:

http://pepsic.bvsalud.org/scielo.php?script=sci a rttext\&pid=S1516 -

$36872013000100002 \& \operatorname{lng}=p t \& n r m=i s o \& t \operatorname{lng}=p t$

27. Berrios GE. A psicopatologia da afetividade: aspectos conceituais e históricos. Rev Latinoam Psicopat Fund. 2012;15(5):138-70.

https://doi.org/10.1590/S1415-

47142012000100011

28. Marcellos CF. Objetivo e método na psicologia de Wilhelm Wundt e Edward Titchener: um comparativo [dissertação]. Juiz de Fora: Universidade Federal de Juiz de Fora; 2012. Disponível em:

http://www.ufjf.br/ppgpsicologia/files/2010/01/ Cintia-Fernandes-Marcellos.pdf

29. Pastrana MM. Comunicar com o Bebé antes de ele nascer através da haptonomia. 2013. Disponível em: http://docplayer.com.br/208586Comunicar-com-o-bebe-antes-de-ele-nasceratraves-da-haptonomia.html 
Nota: Trabalho de conclusão do curso de Graduação em Enfermagem da Universidade Federal de Viçosa - UFV

Recebido em: 16/05/2016

Versão final apresentada em: 14/08/2017

Aprovado em: 21/08/2017

\section{Endereço de correspondência:}

Letícia Ábdon Caldeira

Rua 16, no 233, apto 103 - Bairro Loanda

CEP: 35930-002 João Monlevade/MG - Brasil

E-mail: leticia.abdon@hotmail.com 